\title{
A COMPARATIVE ANALYSIS OF A CONVENTIONAL SUSPENSION SYSTEM WITH AN INERTER BASED CONVENTIONAL SUSPENSION SYSTEM FOR A PASSENGER CAR.
}

\author{
Lalit Pankaj Grover \\ Master's Student of Automotive Systems \\ HAN University of Applied Sciences, Ruitenberglaan 31, 6826 CC Arnhem, Netherlands
}

\begin{abstract}
This paper discusses the impact of adding an inerter to the conventional suspension system for a passenger car. The Inerter was recently introduced as an ideal mechanical twoterminal element which is a substitute for the mass element with the applied force, proportional to the relative acceleration across the terminals. Till now, ideal Inerters have been applied to Formula 1 cars, motorcycle and train suspension systems, in which significant performance improvement was achieved. This paper explores the effect of adding an inerter (in series) to the conventional suspension system for a passenger car in terms of ride comfort by comparing the amplitude of displacement and jerk of sprung and unsprung mass.

This is accomplished by comparing the ride comfort of a quarter-car model with a conventional suspension system to the ride comfort of a quarter-car model with an inerter added in series.
\end{abstract}

Keywords: Inerter or J-damper, b -inertance constant.

\section{INTRODUCTION}

The suspension system of a passenger car or any performance oriented car forms a vital interface between the road and the vehicle. Suspension system keeps the wheel in contact with the driving surface, thus providing comfort to passengers and the handling performance to the driver (grip). On contrary to Formula 1 cars where handling is no longer a concern, more preferably the suspension system is required to achieve maximum comfort performance for a passenger car. The suspension system handles mainly three degrees of freedom of a vehicle: yaw (linear in a vertical direction), pitch (rotational about a lateral axis), and roll (rotational about a longitudinal axis).
The suspension system in an automobile has dual purpose. It minimizes the acceleration of the vehicle body for a comfortable ride to the passengers by isolating them from the road irregularities (vibrations), bumps, and potholes, and simultaneously improving the road holding capacity of the vehicle providing safety. No matter how the suspension system is tuned, there is always a compromise between the two characteristics of a vehicle i.e. handling (grip of tyres) and comfort.

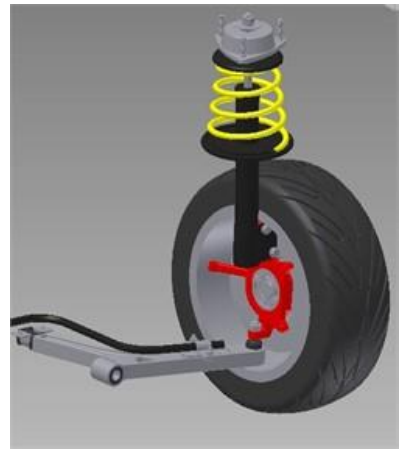

Figure 1: Conventional suspension system [6].

This research focuses on the conventional suspension system of a passenger cars (in the context of comfort performance) as every technology is incorporated from the racing world to the commercial vehicles (passenger cars). The conventional suspension systems used in the passenger car are although effective and stiff, which leads to spring backs effects in the suspension that cannot be damped. These spring back effects are due to the load variations in the contact patch, the wheel does not always have optimum contact with the road surface (vertical motion of wheel), resulting in less grip of tires on road and reduced power transfer. Now, the question arises why inerter is used with the suspension system? This question is answered in the research by prof. M. C. Smith [1], in the mechanical electrical analogies. M.C. Smith constructed a 


\section{International Journal of Engineering Applied Sciences and Technology, 2021 \\ Vol. 6, Issue 1, ISSN No. 2455-2143, Pages 122-128 \\ Published Online May 2021 in IJEAST (http://www.ijeast.com)}

physical representation of an ungrounded capacitor in an electrical circuit, called the inerter. An Inerter shown in Fig. 2, is an ideal mechanical two-terminal element that is a substitute for the mass element in mechanical/electrical analogy, with the defining equation as follows:

$$
F=b\left(\dot{v}_{2}-\dot{v}_{1}\right)
$$

Where, $F$ is the applied force and $\mathrm{b}$ is inertance constant in $\mathrm{kg}$, while $v 1$ and $v 2$ are the velocities of the two terminals in $\mathrm{m} / \mathrm{s}$.

To damp these spring back effects in the suspension system, 'J-damper' was used as a mechanical suspension element by McLaren [1]. Typically in Formula 1 racing cars, a mechanical device ' $\mathrm{J}$ damper' is used with the suspension system for improving the handling performance. Thus integrating the application of the J-damper (Inerter) in a passenger car has so far not been investigated. Hence, this research is about the effect of adding an inerter into the conventional suspension system of a passenger car. This is done by developing two different configurations of a quarter-car model; one with an inerter and other without an inerter, in which it is considered all the four wheels are decoupled.

The rest of the paper is organized as follows. We first present some background on Inerters in Section II. We then introduce a vehicle suspension model, the quarter-car model, modelled conventional suspension system and inerter based suspension system in Section III. Further, section VI deals with the input and output of the modelled suspension system. Section $\mathrm{V}$ deals with the results and discussion of the research. Conclusions are given in Section VI.

\section{BACKGROUND ON INERTERS}

In modelling, all engineering domains are treated alike, since energy exchange between systems can be generalised. The basic analogy between mechanical and electrical circuits, force is related to current as the 'through-variables' and velocity to voltage as the 'across-variables' [9]. Using the force current analogy, mass relates to a grounded capacitor, spring to an inductor and damper to a resistor. In this analogy, the mass element, together with the spring and damper, is inadequate to exactly relate the two domains. The mass element, seen as a grounded capacitor does not complete the analogy

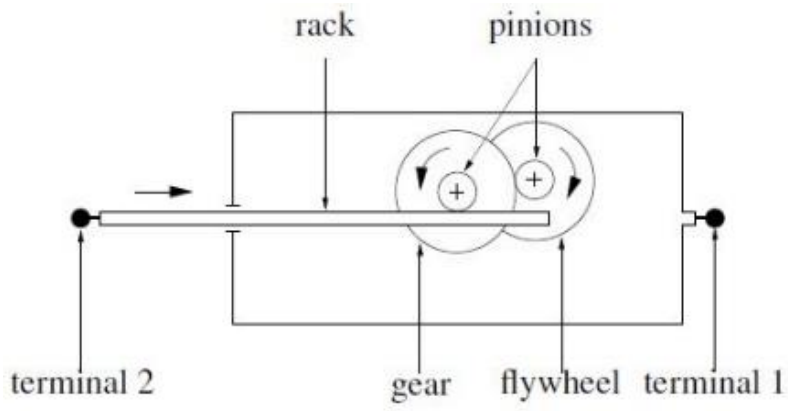

Figure 2: Schematic diagram of Inerter [1].

since the capacitor should be a two-terminal element.

To complete the analogy, the inerter was introduced [5]. Contrary to a mass element, the inerter is a two terminal element analogous to an ungrounded capacitor, with independently movable terminals. The following table demonstrates the force current analogy with ' $S$ ' being the standard Laplace transform variable.

\begin{tabular}{|c|c|c|c|}
\hline \multicolumn{2}{|c|}{ Mechanical } & \multicolumn{2}{|c|}{ Electrical } \\
\hline $\begin{array}{l}\overrightarrow{v_{2}} \\
\frac{d F}{d t}=k\left(v_{2}-v_{1}\right)\end{array}$ & $\begin{array}{l}Y(s)=\frac{k}{s} \\
\text { spring }\end{array}$ & $\begin{array}{l}i \vec{v}_{2} \\
\frac{d i}{d t}=\frac{1}{L}\left(v_{2}-v_{1}\right)\end{array}$ & $\begin{array}{l}Y(s)=\frac{1}{L s} \\
\text { inductor }\end{array}$ \\
\hline 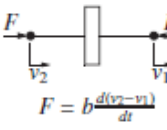 & $\begin{array}{c}Y(s)=b s \\
\text { inerter }\end{array}$ & $\begin{array}{l}\stackrel{i}{v_{2}}|| \overrightarrow{v_{1}} \\
\quad i=C \frac{d\left(v_{2}-y_{1}\right)}{d t}\end{array}$ & $\begin{array}{l}Y(s)=C s \\
\text { capacitor }\end{array}$ \\
\hline $\begin{array}{l}\underset{v_{2}}{F} \\
F=c\left(v_{2}-v_{1}\right)\end{array}$ & $\begin{array}{l}Y(s)=c \\
\text { damper }\end{array}$ & $\begin{array}{l}v_{2} \\
i=\frac{1}{R}\left(v_{2}-v_{1}\right)\end{array}$ & $\begin{array}{l}Y(s)=\frac{1}{R} \\
\text { resistor }\end{array}$ \\
\hline
\end{tabular}

Figure 3: Analogies [5].

The inerter can be defined as a mechanical device in which the applied force at the terminals is proportional to the relative acceleration between the terminals.

\section{VEHICLE SUSPENSION MODEL}

As stated in section I, this paper explores, how adding inerter to a conventional suspension system effects the comfort performance of a passenger car which is done by comparing two different suspension system configurations (of a quarter-car model [11]), one with inerter and one without inerter. However, the external forces are not considered for analysing the performance of both the suspension systems.

The dynamic behaviour of a vehicle can be modelled using various car models, like the quarter car, half car and full car model, all with different degrees of 
freedom. Every model has its own configuration and different types of dynamic behaviour can be investigated. The quarter car model is the most simplified vehicle model, representing only one fourth of a vehicle. Vertical dynamic behaviour can be easily investigated, but the influence of, for example, roll, pitch or the position of the centre of gravity cannot be investigated with this model. This model needs to be extended to a half or even a full car model for roll analysis.

Both the quarter-car models (with inerter \& without inerter) are modelled using the Newtonian approach. Furthermore, the influence of the inerter will be investigated to analyse if the inerter improves the comfort performance of a passenger car or not. Finally, the conclusion is drawn about the performance of the inerter in the used suspension configuration.

\section{A. The quarter-car model}

The most employed and useful model of a vehicle suspension system is a quarter-car model [1] [11]. A quarter-car model is a model of a quarter of a car, including one wheel, one suspension system, and the weight of a quarter of the car. This quarter-car model is less complex but not as accurate as a full-car model or a half-car model. For this research, the quarter-car model will be sufficient. Fig. 4, shows a general quarter-car model.

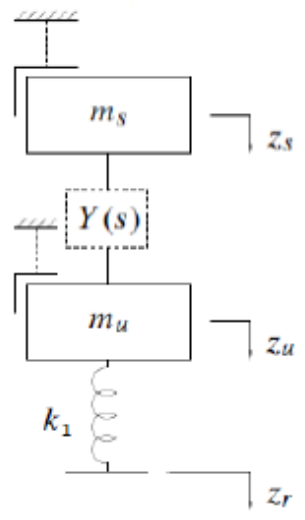

Figure 4: Quarter car model [1].

Different configurations can be chosen for $\mathrm{Y}(\mathrm{s})$. It has to be decided which two configurations of $\mathrm{Y}(\mathrm{s})$ will be used to study the effect of the inerter on ride comfort [1] [12]. As mentioned in the introduction, two suspension system configurations will be evaluated. The first without an inerter and the second with inerter. These configurations will be implemented into a quarter-car model to examine the performance. In this section, both suspension configurations will be discussed.
B. Modelled conventional suspension system

The first configuration, with a spring and damper in a parallel manner, is a conventional configuration used in many passenger vehicles. This configuration is also used in various papers to evaluate improvements made for vehicle suspension systems. Based on M.C. Smith paper [1] [3] [10], the decision is made to use the parallel configuration of spring and damper, for analysing the performance of the suspension system on a passenger car.

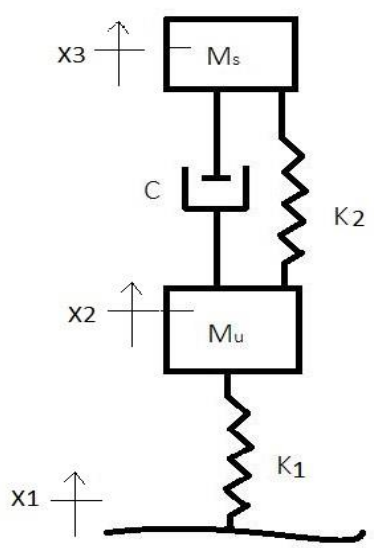

Figure 5: Conventional Suspension System [1].

Considering, $\boldsymbol{x}_{\mathbf{1}}$ as the road undulation displacement which acts as the input for the system. The equations of motion are developed and are described below.

$$
\begin{gathered}
m_{s} \ddot{x}_{3}=k_{2}\left(x_{2}-x_{3}\right)+c\left(\dot{x}_{2}-\dot{x}_{3}\right) \\
m_{u} \ddot{x}_{2}=-k_{2}\left(x_{2}-x_{3}\right)-k_{1}\left(x_{2}-x_{1}\right)-c\left(\dot{x}_{2}-\right. \\
\left.\dot{x}_{3}\right)
\end{gathered}
$$

Where,

$m_{s}-$ Sprung mass in $(\mathrm{kg})$

$m_{u}-$ Unsprung mass in $(\mathrm{kg})$

$\boldsymbol{k}_{\boldsymbol{l}}$ - Tyre stiffness in $(\mathrm{N} / \mathrm{m})$

$\boldsymbol{k}_{2}$ - Spring stiffness in $(\mathrm{N} / \mathrm{m})$

$\boldsymbol{c}$ - Damping Constant in (Ns/m)

C. Modelled conventional suspension system with an inerter in series.

The second configuration, with an inerter in series is used for evaluating the comfort performance of the passenger cars. The inerter is positioned in series 


\section{International Journal of Engineering Applied Sciences and Technology, 2021 \\ Vol. 6, Issue 1, ISSN No. 2455-2143, Pages 122-128 \\ Published Online May 2021 in IJEAST (http://www.ijeast.com)}

with the damper. In reference to M. C. Smith [1] [10], there are seven suspension system configurations with the inerter, which are compared to the conventional suspension configurations.

As it is not known what type of suspension configuration is used in passenger cars, as there is no pervious data available to this context? Fig. 6 shows a quarter-car model with a suspension system containing an inerter.

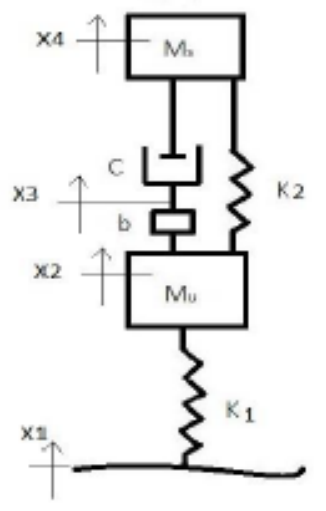

Figure 6: Inerter based suspension system [1].

Considering, $x_{1}$ as the road undulation displacement which acts as the input for the system. The equations of motion are developed and are described below.

$$
\begin{gathered}
m_{s} \ddot{x}_{4}=-k_{2}\left(x_{4}-x_{2}\right)-c\left(\dot{x}_{4}-\dot{x}_{3}\right) \\
m_{u} \ddot{x}_{2}=-k_{2}\left(x_{2}-x_{4}\right)-b\left(\ddot{x}_{2}-\ddot{x}_{3}\right)-k_{1}\left(x_{2}-\right. \\
\left.x_{1}\right) \\
-c \dot{x}_{3}+c \dot{x}_{4}+b \ddot{x}_{2}=b \ddot{x}_{3}
\end{gathered}
$$

Where,

$m_{s}-$ Sprung mass in $(\mathrm{kg})$

$m_{u}-$ Unsprung mass in $(\mathrm{kg})$

$\boldsymbol{k}_{\boldsymbol{l}}$ - Tyre stiffness in $(\mathrm{N} / \mathrm{m})$

$\boldsymbol{k}_{2}$ - spring stiffness in $(\mathrm{N} / \mathrm{m})$

$\boldsymbol{c}$ - Damping Constant in (Ns/m)

$\boldsymbol{b}$ - Inerter Constant in $(\mathrm{kg})$

\section{INPUT TO THE MODEL (ROAD PROFILES)}

Two different road inputs are defined for the models explained above. The first road input is a bump, which represents driving over a speed breaker or pothole on a highway/motorway. The second road input is a sine wave, representing the normal road profile depending on the road texture (micro or macro). Different vehicle models are simulated for a specific range of speeds and frequencies.

\section{A. Bump Input}

A simple way to simulate a road profile is to use a step or impulse response as there is no physical model to carry out testing. A step contains all frequencies and is, therefore, an obvious choice. The step time of 1 second is used for simulating the result of the models as a reference. Mathematically, the input of both of the models is denoted by $\boldsymbol{x} \mathbf{1}$.

\section{B. Sinewave Input}

For dynamic testing of the suspension performance on a road, a sine wave is the simplest simulation possible. Also, in simulation studies, a sine wave can better approximate the irregularities of the road. Knowledge of the excitation for the motion on uneven road is important for the study of riding comfort [8] [13]. Road excitation reduces the ability of the tires to exert forces in the $\boldsymbol{x}$ and $\boldsymbol{y}$ direction, because it causes a variable normal load $\boldsymbol{F z}$, and increases the stressing of the structural elements (springs, damper). Such excitation cannot be studied with a deterministic approach. Therefore, following methods used for random vibrations must be applied [7] [13].

For experimental measurement of the road profile, a law $\boldsymbol{h}(\boldsymbol{x})$ can be defined and its power spectral density found through harmonic analysis which is not the function of time. Mathematically, the input of both of the models is denoted by $\boldsymbol{x} \mathbf{1}$.

While considering a sine wave it is important to know the amplitude and frequency of the wave [8].

$$
h(x)=h_{o} \sin (\omega t+\varnothing)
$$

Where,

$\boldsymbol{h}_{\boldsymbol{o}}$ - Road irregularity amplitude in (m).

$\boldsymbol{\omega}$ - Angular frequency in (rad/s).

$\emptyset$ - Phase off-set in (rad).

$$
\omega=\frac{2 \pi v}{L}
$$

$$
\begin{aligned}
& \boldsymbol{v} \text { - Vehicle Speed in }(\mathrm{m} / \mathrm{s}) . \\
& \mathbf{L} \text { - Length of road irregularity in }(\mathrm{m}) \text {. }
\end{aligned}
$$


Table 1: Data of road amplitude and length of road irregularity is taken from statistical data [9].

\begin{tabular}{|c|c|c|}
\hline $\begin{array}{c}\text { Types of } \\
\text { road }\end{array}$ & $\boldsymbol{h}_{\boldsymbol{o}}(\mathbf{m m})$ & $\mathbf{L}(\mathbf{m})$ \\
\hline $\begin{array}{c}\text { Highway / } \\
\text { Motorway }\end{array}$ & $10-20$ & $10-15$ \\
\hline Urban roads & $10-20$ & $1.0-2.0$ \\
\hline $\begin{array}{c}\text { Pavement } \\
\text { roads }\end{array}$ & $30-40$ & $0.15-0.30$ \\
\hline Off roads & $50-70$ & $0.10-0.15$ \\
\hline
\end{tabular}

A highway/motorway will preferably have the rough road surface i.e. a slightly higher value of amplitude. This amplitude of the road depends on the texture of the road whether its micro or macro. For this project amplitude is taken as $0.02 \mathrm{~mm}$ [8], because it is considered as the vehicle is riding on highway.. The frequency of the wave depends on the speed of the vehicle. Considering a speed of $30 \mathrm{~km} / \mathrm{h}$, the frequency of the wave results to be $3.48 \mathrm{rad} / \mathrm{secs}$ by using the above formula mentioned in equation (8).

\section{Parameters used for simulation}

To observe the dynamic characteristics of both the systems, initial value of parameters of the quartercar models need to be defined. Hence the following parameters are considered based on the research paper [1].

Table 2: Parameters used for simulation [1].

\begin{tabular}{|c|c|c|c|}
\hline $\begin{array}{c}\text { Tyre } \\
\text { stiffness } \\
\left(\mathrm{K}_{1}\right)\end{array}$ & $\begin{array}{c}\text { Suspension } \\
\text { stiffness } \\
\left(\mathrm{K}_{2}\right)\end{array}$ & $\begin{array}{c}\text { Sprung } \\
\text { mass } \\
(\mathrm{Ms})\end{array}$ & $\begin{array}{c}\text { Unsprung } \\
\text { Mass } \\
(\mathrm{Mu})\end{array}$ \\
\hline $150 \mathrm{KN} / \mathrm{m}$ & $120 \mathrm{KN} / \mathrm{m}$ & $250 \mathrm{~kg}$ & $35 \mathrm{~kg}$ \\
\hline
\end{tabular}

\section{OUTPUT OF THE MODEL}

To analyse the output of the quarter-car model, one can distinguish between two measures, the first one being ride comfort and the second one, road holding. Comfort can determine the magnitude of vibrations transferred from the road to the driver. This has an influence on the health of the driver. Road holding is used to determine the performance of the suspension system. Road holding has an influence on the ability of the tyre to transfer load in the lateral and longitudinal direction. To establish an optimal suspension design, one has to compromise between the two. As mentioned above, this research is about investigating the effects of comfort performance when adding an inerter to the conventional suspension system in a passenger cars. Hence, here the focus is on ride comfort.

\section{RESULTS AND DISCUSSION}

In section III, the equations of motion are derived for both the models. Both the model are defined for a quarter-car with a conventional suspension system and for a quarter-car with an inerter. This section looks into the characteristics of these two modelled systems. In section of road inputs (see section IV) it is stated that both a step response and a sine wave response will be used for simulation of the model.

First the bump (step) road input is applied to the quarter-car models. The step response of the displacement for both the models are shown in Fig. 7. It is observed that the inerter based suspension system has significantly higher amplitude of the displacement which means there is no improvement in the ride comfort of a passenger car. In other words, it can also be seen that there are severe oscillations in the inerter based model due to which it results into no comfort. This shows that the step response of the system without the inerter performs better than that of the system with the inerter.

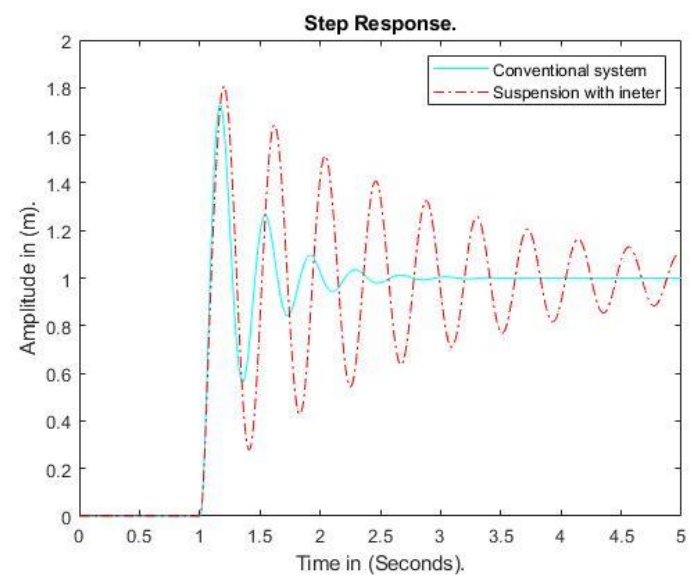

Figure 7: Step input response for displacement.

Similarly, the bump (step) road input is applied to the quarter-car models for analysing the jerk in both the models. The step response of the jerk for both the models are shown in Fig. 8. Looking at the step response, it can be said that the inerter based suspension system has significantly higher amplitude of jerk (abrupt oscillations) which means that the conventional suspension system has a better performance compared to the inerter based suspension system. In other words, there is no improvement in the ride comfort of a passenger car when an inerter is added in series to the conventional suspension system. This illustrates that the step response of the system without the inerter performs better than that of the system with an inerter. 


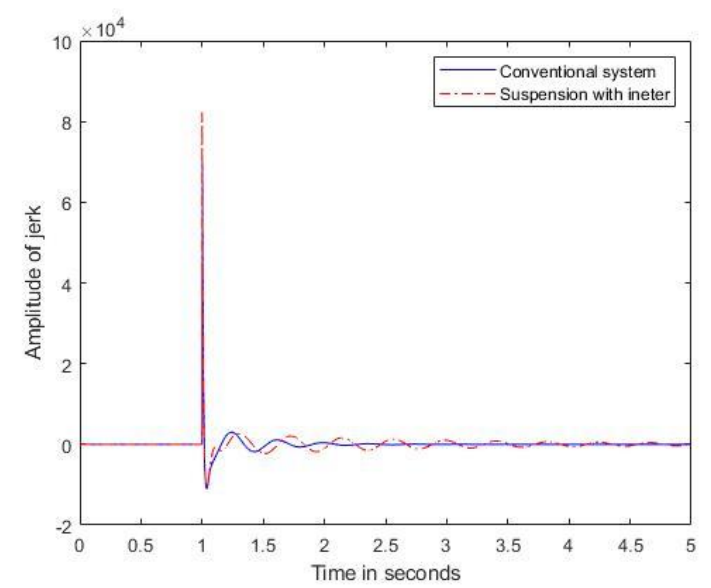

Figure 8: Step input response for jerk.

As stated in the section of road profile (see section IV), while considering the sinewave response for both the systems we need to define the road condition, speed of a car for finding the amplitude and frequency of the wave. Referring to the section of sinewave input (see section IV (B)) already the conditions are defined that the car is travelling with a speed of $30 \mathrm{~km} / \mathrm{hr} \&$ frequency as $3.48 \mathrm{rad} / \mathrm{sec}$ on a highway. Moreover, the amplitude of the wave is considered as $0.02 \mathrm{~m}$ (macro-texture) when operating under highway conditions [8]. Looking at the sinewave response shown in Fig. 10, it can be said that the inerter based suspension system has higher peaks of displacement amplitude in between time 0 - 1.5 secs because the displacement amplitude exceeds the given amplitude due to higher undulations in the road profile. In other words, it can be said that the inerter based model does not improve the ride comfort of a passenger car. This shows that the sinewave response of the system without the inerter performs better than that of the system with the inerter.

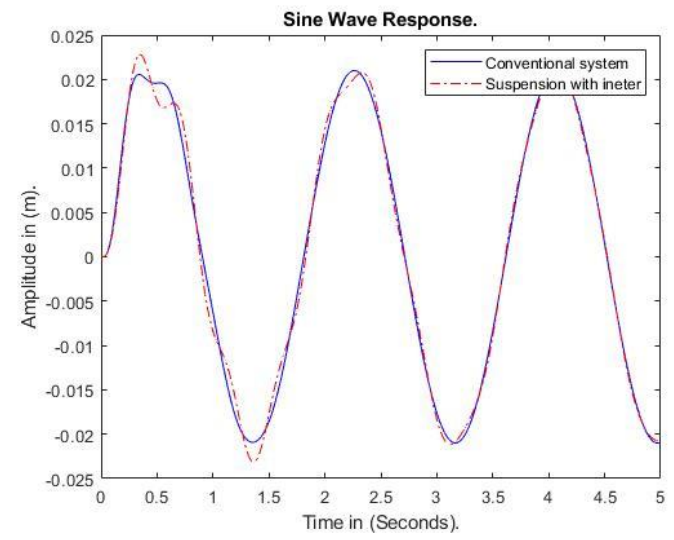

Figure 9: Sinewave input response for displacement.

Further, when plotting the sinewave response of the jerk (derivative of acceleration) shown in Fig. 10, the inerter based suspension model shows abrupt oscillations in the system due to which it does not improve the comfort characteristics of a passenger car. These higher oscillations in the inerter based system can be damped to certain extent using the filters in simulation. Still looking at the response shown in Fig.10, does not show any improvement towards the ride comfort of a passenger car.

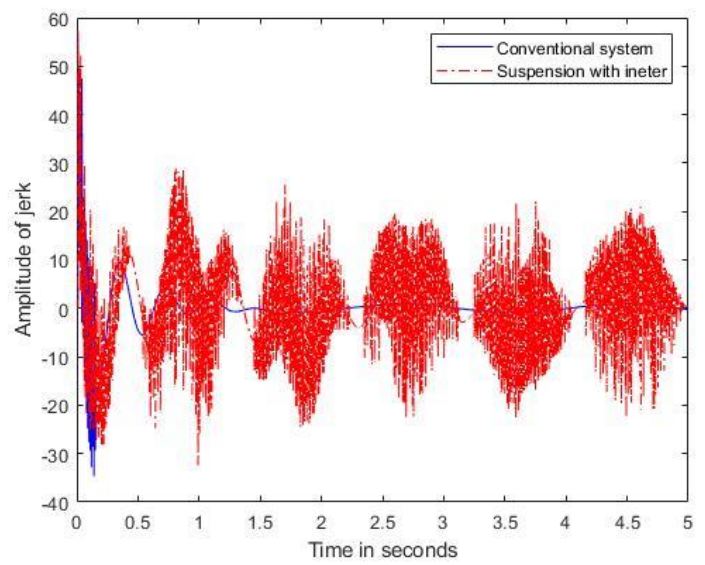

Figure 10: Sinewave response for jerk.

\section{CONCULSIONS}

This paper explores how adding an inerter ( $\mathrm{J}$ damper) in series to a conventional suspension system changes the ride comfort characteristics of a passenger car. This is accomplished by comparing the displacement, jerk (derivative of acceleration) of a quarter-car model with a conventional suspension system to the displacement, jerk (derivative of acceleration) of a quarter-car model with a conventional suspension system with an inerter added in series.

Looking at the step response of both the models, the amplitude of (displacement, jerk) the system with the inerter is considerably higher. This means that more vibrations are transferred from the road to the vehicle body. In other words, the performance of the conventional suspension system decreases when adding an inerter in series.

In addition, looking at the sine wave response the performance of the system with an inerter is degraded as there are more oscillations in the amplitude of wave than that of the conventional suspension system.

In a nutshell, it can be observed that adding an inerter in series to the conventional suspension system does not improves the comfort performance of a passenger car, regardless of which input to the model (bump or road profile) is chosen. In this project, only one configuration of a suspension system with an inerter is investigated. To be able to 
find out if another configuration performs better, additional research needs to be done.

\section{REFERENCES}

[1] Smith M.C and Wang F.C, (2004) "Performance Benefits in Passive Vehicle Suspensions Employing Inerters", Vehicle System Dynamics 42 (4), pp. 235257.

[2] Wang Fu-Cheng and Su Wei-Jiun, (2008) "Inerter Nonlinearities and the Impact on Suspension Control", American Control Conference Westin Seattle Hotel, Seattle, Washington, USA, doi 978-1-4244-2079-7/08.

[3] Nise N.S, (2014) Control Systems Engineering. Pomona: Wiley 6th Edition.

[4] Tran Thanh-Tung and Hasegawa Hiroshi, (2015) "Advanced Passive Suspension with Inerter Devices and Optimization Design for Vehicle Oscillation", International Journal of Mechanical Engineering and Robotics Research Vol. 4, No. 4.

[5] Smith M.C (2002) "Synthesis of Mechanical Networks", The Inerter. IEEE Transactions on Automatic Control 47, pp. 1648-1662.

[6] Convetional Suspension System: https://www.jvejournals.com/article/19238. (08/04/2019).
[7] Road Profile: https://x-engineer.org/automotiveengineering/chassis/vertical-dynamics/road-profilemathematical-modeling-for-wheel-verticaldynamics-simulation/ (03/04/2018).

[8] Genta Giancarlo and Morello L, (2016) The Automotive Chassis. Vol. 2. System Design, Springer, ISBN 9402404848.

[9] Smith M.C, (2008) "Secrets of the inerter revealed", University of Cambridge, Vehicle dynamics system, pp. 235-257.

[10] Wolf H. Jokic M. Alujevic N. Cakmak D., (2018) "Passive and active vibration isolation systems using inerter". In: Journal of Sound and Vibration 418, pp. 163-183.

[11] Pauwelussen J.P. Essentials of Vehicle Dynamics. Elsevier Science and Technology, 2014, p. 29. ISBN:9780081000366.

[12] Wang Y. Dong Y. Li C. Liang M., (2011) "Vibration suppression using two-terminal flywheel, Part II: Application to vehicle passive suspension" In: Journal of Sound and Vibration 18(9), pp. 1353-1365.

[13] Edel Matthew, (2014) "Road Profile Sensor: A detection method for active suspension systems", Seattle Pacific University, Honors Project, pp. 510. 